\title{
Nilai-nilai pendidikan ibadah perspektif Muhammad Bin Shalih al-Utsaimin
}

Azis a,1, Beni Riswandi a,2

*a Sekolah Tinggi Agama Islam Masjid Syuhada, Yogyakarta, Indonesia;

${ }^{1}$ azisabdullah2018@gmail.com; ${ }^{2}$ beniriswandi@gmail.com

*Correspondent Author

Received:

Revised:

Accepted:

\section{KAT A KUNCI}

Nilai

Penidikan ibadah

Bulan ramadhan

keutamaan
KEYWORDS

Values

Worship education

Ramadan

Virtue

\section{ABSTRAK}

Penelitian ini bertujuan untuk mengkupas nilai-nilai yang terkandung dalam kitab majalis syahru ramadhan. Penelitian berjenis penelitian library research, dengan teknik pengumpulan data dokumentasi dan analisisnya dengan metode content analisys. Hasil penelitian terdapat lima nilai-nilai pendidikan ibadah dalam kitab majālis syahru ramadhān, yaitu nilai pendidikan ibadah puasa, nilai pendidikan ibadah shalat malam, nilai pendidikan ibadah membaca Al-Qur'an, nilai pendidikan ibadah zakat fitri, dan nilai pendidikan ibadah i'tikaf.

\section{The values of worship education from the perspective of Muhammad bin Salih al-Utsaimin}

This study aims to explore the values contained in the book of Majalis Shahru Ramadhan. This type of research is library research, with documentation data collection techniques and analysis using the content analysis method. The results showed that there were five values of worship education in the book of Majālis Shahru Ramadan, namely the value of fasting worship education, the value of evening prayer education, the educational value of reading the Qur'an, the education value of zakat fitri worship, and the value of i'tikaf worship education.

\section{Pendahuluan}

Pendidikan ibadah merupakan pendidikan yang sangat penting untuk dipelajari serta diamalkan dalam kehidupan seorang muslim setiap harinya. Karena hikmah terbesar penciptaan manusia dan jin adalah hanya beribadah kepada Allah semata(Saifudin Hakim, 2019) dan tidak menyekutukan-Nya dengan sesuatu apapun. Dalam pendidikan ibadah umat Islam telah memiliki teladan terbaik yang patut dicontoh oleh mereka dalam semua aspek kehidupan terutama dalam masalah ibadah, yaitu Rasulullah Muhammad Shalallahu'alaihi Wa Sallam.

Bulan Ramadhan adalah bulan yang penuh dengan barakah dan penuh dengan keutamaan(Subrata \& Dewi, 2017). Allah ta'ala telah mensyariatkan dalam bulan tersebut berbagai macam amalan ibadah yang banyak agar manusia semakin mendekatkan diri kepada Allah. Akan tetapi sebagian dari kaum muslimin berpaling dari keutamaan ini dan membuat cara-cara baru dalam beribadah. Mereka lupa firman Allah ta'ala dalam surat al- 
Maidah ayat 3 bahwasanya agama Islam telah disempurnakan oleh Allah ta'ala. mereka ingin melalaikan manusia dari ibadah yang disyariatkan. Mereka tidak merasa cukup dengan apa yang dicontohkan Rasulullah shalallahu'alaihi wasallam dan para shahabat beliau radhiallahu'anhum. Melaksanakan ibadah dengan ikhlas mengharapkan balasan dari Allah semata(Lismijar, 2019) dan mencontoh ibadah yang telah diajarkan Rasulullah shalallahu'alaihi wasallam merupakan dua syarat diterimanya(al Anwar, 2018) amalan ibadah disisi Allah ta'ala. Namun sayangnya banyak kaum muslimin yang tidak mengetahui hal ini. Oleh karena itu wajib bagi setiap muslim atau muslimah untuk mempelajari tentang ibadah yang ia lakukan agar diterima Allah ta'ala, terkhusus rangkaian ibadah dibulan Ramadhan.

Kitab Majālis Syahru Ramadhān Muhammad bin shalih Al-Utsaimin ini berisi pembahasan ilmu seputar bulan ramadhan yang terdiri dari tiga puluh pembahasan yang berbedabeda setiap pembahasannya, seperti keutamaan bulan Ramadhan, keutamaan ibadah puasa, hukum puasa Ramadhan, qiyam di bulan Ramadhan, adab berpuasa, sifat penduduk surga, zakat fitri dan sebagainya.

\section{Metode}

Jenis penelitian ini adalah library research(Ramanda et al., 2019) yaitu serangkaian kegiatan yang berkenaan dengan metode pengumpulan data pustaka, membaca dan mencatat serta mengolah bahan penelitian. Penelitian ini untuk mengumpulkan data kepustakaan, seperti : buku-buku, majalah, dokumen, catatan dan kisah-kisah sejarah dan lain-lainnya. Fokusnya mengkaji nilai-nilai pendidikan ibadah dalam kitab Majaalis Syahru Ar-Ramadhan karya syaikh Al-Utsaimin rahimallahu. Pendekatannya dengan pendekatan psikologis(Mansir, 2018), yaitu cara pandang psikologi terhadap berbagai fenomena dan dimensi-dimensi tingkah laku baik dilihat secara individual, sosial maupun pendidikan.

Teknik pengumpulan data dengan dokumentasi(Prasanti, 2018) yaitu cara mengumpulkan data primer dan sekunder. Langkah-langkah teknik dokumentasi dengan check-list untuk mencari variabel yang sudah ditentukan dan peneliti membubuhkan tanda check di tempat yang sesuai. Untuk mencatatat hal-hal yang bersifat bebas atau belum ditentukan dalam daftar variavel peneliti dapat menggunakan kalimat bebas. Analisis Analisis datanya dengan metode content analisys, yaitu suatu metode yang dilakukan dengan membuat inferensi secara kontekstual. Menurut Suharsimi Arikunto metode analisis isi(Febriansyah, 2017) adalah metode penelitian yang dilakukan terhadap informasi yang didokumentasikan dalam rekaman, baik gambar, suara, tulisan, atau bentuk rekaman lainnya.

Menurut Hadari Nawawi sebagaimana yang dikutip oleh Soejono dan Abdurrohman(Syamsudin, 2019), prosedur analisis isi dilakukan dengan langkah-langkah sebagai berikut menyeleksi teks yang akan diseleksi, menyusun item-item yang spesifik tentang isi dan bahasa yang akan di selidiki sebagai alat pengumpulan data, melaksanakan penelitian dan mengetengahkan kesimpulan sebagai hasil analisis.

\section{Hasil dan Pembahasan}

\section{Kajian Teori}

Menurut Kaswardi nilai adalah sesuatu yang dinilai positif, dihargai, dipelihara, diagungkan, dihormati, membuat orang gembira, puas bersyukur(Sari, 2019). Istilah nilai berarti "hal-hal atau sifat-sifat yang bermanfaat atau penting untuk kemanusiaan". Nilai diartikan dengan "sifatsifat yang penting atau berguna bagi manusia, sesuatu yang penting atau berguna bagi kemanusiaan, sesuatu yang menyempurnakan manusia sesuai dengan hakikatnya. Menurut W.J. Poerwadarminto nilai adalah sifat-sifat (hal-hal) yang penting atau 
berguna bagi kemanusiaan(Sari, 2019). Pengertian nilai menurut Milton Roceach dan James Bank dalam Kartawisastra adalah suatu tipe kepercayaan yang berada dalam ruang lingkup sistem kepercayaan, di mana seseorang harus bertindak atau menghindari suatu tindakan, atau mengenai sesuatu yang pantas atau tidak pantas dikerjakan, dimiliki dan dipercayai. Menurut max scheler, nilai-nilai yang ada tidaklah sama luhur dan sama tingginya, nilai-nilai itu secara senyatanya ada yang lebih tinggi dan ada yang lebih rendah dibandingkan dengan nilai-nilai lainnya(Asa, 2019). Menurut tinggi-rendahnya, nilai-nilai di kelompokkan dalam 4 tingkatan sebagai berikut: nilai-nilai kenikmatan, nilai-nilai kehidupan, nilai-nilai kejiwaan dan nilai-nilai kerohanian.

Pendidikan adalah proses pengubahan sikap dan tata laku seseorang atau usaha mendewasakan manusia melalui upaya pengajaran dan pelatihan, proses, cara, perbuatan mendidik. Pendidikan sangat dibutuhkan oleh masyarakat sehingga pemerintah sebagai penyelenggara pendidikan formal selalu memajukan pendidikan bagi masyarakat karena dengan pendidikan diharapkan akan melahirkan manusia-manusia generasi penerus yang bertanggung jawab dan kreatif. Menurut Ki Hajar Dewantara mengartikan pendidikan sebagai tuntunan di dalam hidup tumbuhnya anak-anak(Ulinnuha, 2016). Sedangkan, menurut Driyakarya, pendidikan adalah pemanusiaan manusia muda atau pengangkatan manusia muda ke taraf insan(Ulinnuha, 2016). Sedang menurut prespektif Islam, pengertian pendidikan merujuk pada beberapa istilah, yaitu at-tarbiyah, atta'dib, at-ta'lim ( التربية- التأديب(التعليم). Dari ketiga istilah tersebut, yang paling popular digunakan dalam menyebutkan praktik pendidikan Islam adalah terminology altarbiyah, seperti penggunaan islitilah at-Tarbiyah alIslamiyah yang berarti pendidikan Islam. Muhammad Al-Naquib Al Attas(Muttaqien, 2019), seorang tokoh pemikiran pendidikan Islam, berpendapat sesungguhnya istilah yang paling tepat untuk pendidikan Islam adalah ta'dib sebab struktur konsep ta'dib sudah mencakup unsurunsur ilmu instruksi (ta'lim) dan pembinaan yang baik (tarbiyyah). Berbeda dengan pendapat Al- Attas, Konferensi Internasional Islam di Makkah tahun 1977 mengartikan pendidikan Islam mencakup tiga pengertian sekaligus, yakni tarbiyah, tailim dan ta'dib.

Konsep Ibadah secara bahasa adalah ketundukan dan kerendahan diri. Secara istilah adalah yang dicintai dan diridhoi oleh Allah berupa perkataan dan perbuatan secara dzahir dan batin. Manusia diciptakan oleh Allah hanya untuk beribadah kepada-Nya. Secara harfiah, ibadah dapat diartikan sebagai rasa tunduk (tha'at), melakukan pengabdian (tanassuk), merendahkan diri (khudhu'), menghinakan diri (tadzallul) dan istikhanah. Abu A'la-Maududi menyatakan sebagaimana yang dinukil oleh Rosihin Anwar bahwa ibadah dari akar 'abd yang artinya pelayan dan budak(Ma'ruf, 2016). Jadi, hakikat ibadah adalah penghambaan dan perbudakan. Dalam arti terminologi, ibadah adalah usaha mengikuti hukum-hukum dan aturan-aturan Allah dalam menjalankan kehidupan yang sesuai dengan perintah-perintahNya, mulai akil baligh sampai meninggal dunia. Indikasi ibadah adalah kesetiaan, kepatuhan, penghormatan, serta penghargaan kepada Allah subhanahu wata'ala. Serta dilakukan tanpa adanya batasan waktu serta bentuk khas tertentu. Majelis Tarjih Muhammadiyah mendefinisikan ibadah sebagai upaya mendekatkan diri kepada Allah dengan menaati segala perintah-Nya, menjauhi segala larangan-Nya, dan mengamalkan segala yang diizinkanNya(Miswanto, 2016). Ada ibadah umum dan ada ibadah yang khusus. Ibadah yang umum ialah segala amalan yang diizinkan Allah, sedang kan yang khusus ialah apa yang telah ditetapkan oleh Allah akan perincian-perinciannya, tingkat, dan cara-caranya yang tertentu. Definisi ibadah adalah yang disampaikan Syaikhul Islam Ibnu Taimiyah rahimahullah: "Ibadah adalah sebuah istilah untuk segala sesuatu yang dicintai dan diridhai Allah Ta'ala baik berupa perkataan maupun perbuatan, baik perkara lahir maupun barin". Berdasarkan definisi ini, ibadah dapat dibagi menjadi tiga yaitu ibadah hati (qalbiyah), ibadah lisan (qauliyah), dan ibadah anggota badan (badaniyah). Khauf, raja', mahabbah, tawakal, raghbah, dan rahbah merupakan contoh ibadah qalbiyah. Ucapan tasbih, tahlil, takbir, pujian dan ucapan syukur kepada Allah merupakan contoh ibadah lisaniyah qalbiyah. Adapun ibadah 
shalat, zakat, haji, dan jihat adalah bentuk ibadah badaniyah qalbiyah.

\section{Hasil Penelitian}

Kitab majālis syahru ramadhān sebenarnya tidak hanya berisi tentang pendidikan ibadah di bulan ramadhan. Namun peneliti lebih fokus membahas tentang nilai-nilai pendidikan ibadah karena merupakan tema penelitian yang diangkat.

a. Nilai Ibadah Puasa Ramadhan

Puasa Ramadhan merupakan salah satu bagian dari rukun Islam dan bangunannya yang agung. Nabi Shalallahu 'alaihi Wa Sallam bersabda yang artinya "Islam itu dibangun diatas lima besar; kesaksian bahwa tidak ada sembahan yang benar kecuali Allah dan bahwa Muhammad adalah utusan Allah; menegakkan shalat; menunaikan Zakat; menunaikan haji ke Baitullah; dan puasa Ramadhan."

Puasa ini hanya diwajibkan ketika sudah dapat dipastikan masuknya bulan ramadhan, dan tidak boleh melakukan puasa sebelum masuknya bulan ini. Nabi shalallahu 'alaihi wa sallam bersabda yang artinya "Janganlah salah seorang di antara kalian mendahului Ramadhan dengan puasa sehari atau dua hari. Kecuali jika ada seseorang yang memang sudah terbiasa berpuasa, maka silakan saja ia berpuasa (sunah) pada hari itu." (HR. Bukhari)

Nilai ibadah puasa yang terdapat dalam kitab majālis syahru ramadhān, yaitu:

1) Mendekatkan diri kepada Allah

Hikmah puasa adalah ibadah kepada Allah subhanahu wa ta'ala yang dilaksanakan oleh hamba untuk mendekatkan diri kepada-Nya, dengan cara meninggalkan segala hasrat dan keinginan nafsu, yang berupa makanan, minuman dan bersenggama. Maka akan terlihat kesungguhan imannya, kesempurnaan ibadahnya kepada Allah, kekuatan cintanya kepadaNya serta harapannya di sisi-Nya. Manakala seorang mukmin mengetahui bahwa ridha Allah itu ada pada ibadah puasa dengan cara meninggalkan syahwatnya, maka mukmin tersebut berarti lebih mendahulukan kecintaanya kepada Tuhannya daripada mengikuti hawa nafsunya. Orang tersebut rela meninggalkannya sekalipun dirinya sebenarnya senang mengikuti hawa nafsunya. Ini semata dilakukan karena kenikmatan dan kedamaian jiwa yang dirasakannya adalah bilamana dirinya mampu meninggalkan hal itu semata karena Allah.

2) Melahirkan Ketaqwa'an

Hikmah puasa dapat melahirkan ketakwaan. Allah subhanahu wa ta'ala berfirman dalam surat Al Baqarah ayat 183 yang artinya "Wahai orang-orang yang beriman, diwajibkan atas kamu berpuasa sebagaimana diwajibkan atas orang-orang sebelum kamu agar kamu bertakwa." Orang yang berpuasa itu diperintahkan agar melaksanakan ketaatan dan menjahui segala kemaksiatan. Nabi shallallahu 'alaihi wa sallam bersabda yang artinya "Siapa yang tidak bisa meninggalkan ucapan Zur dan kejahilan, maka Allah tidak butuh kepada amalan meninggalkan makanan dan minuman (puasa) yang dilakukannya." (hadits riwayat Al Bukhari)

Seorang yang berpuasa jika benar-benar merasakan bahwa dirinya sedang menjalankan puasa, dan ingin berbuat kemaksiatan, maka orang tersebut akan ingat bahwa dirinya sedang berpuasa, sehingga segera menahan diri dari berbuat maksiat. Oleh karena itu Rasulullah shallallahu 'alihi wa sallam menyuruh orang yang sedang berpuasa ketika ada seseorang yang mencacinya agar mengatakan: "Aku orang yang berpuasa", sebagai peringatan baginya bahwa orang yang sedang berpuasa itu diperintah untuk menahan diri dari tindakan mencaci dan mencela, di samping juga sebagai peringatan bagi dirinya yang sedang menjalankan puasa, sehingga harus menahan diri dari membalas celaan orang lain terhadap dirinya.

3) Hati Selalu Berdzikir kepada Allah

Hikmah lainnya hati akan selalu berzikir. Sebab, sebaliknya, memenuhi syahwat akan melahirkan kelalaian, dan bahkan barangkali akan membuat hati menjadi keras dan buta dari melihat kebenaran. Oleh karena itu, Rasulullah shallalahu 'alaihi wa sallam memberikan 
petunjuk agar makan dan minum ala kadarnya. Nabi Shallallahu 'Alaihi Wa Sallam bersabda yang artinya "Tidak ada bejana yang lebih jelek yang diisi anak Adam dari perut. Cukuplah kiranya beberapa suap makanan baginya untuk menegakkan tulang punggungnya. Jika tidak dapat dihindarkan, maka sepertiga isi perutnya itu untuk makanan, sepertiganya untuk minuman dan sepertiganya lagi untuk pernapasan." (hadits riwayat Ahmad, Nasai dan Ibnu Majah)

4) Mengetahui Kebesaran Nikmat Allah

Hikmah lainnya orang yang kaya akan mengetahui kebesaran nikmat Allah yang telah dianugerahkan oleh-Nya. Allah subhanahu wa ta'ala telah memberikan nikmat kepadanya untuk bisa makan, minum dan bersetubuh, banyak manusia lain yang tidak bisa menikmatinya. Dengan demikian akan memuji Allah atas nikmat ini serta bersyukur kepadaNya atas kemudahan yang diberikan oleh-Nya. Selanjutnya akan ingat kepada saudaranya yang miskin, sehingga tumbuh rasa kedermawanan dirinya untuk kemudian bersedekah, memberikan pakaian dan memenuhi kebutuhan orang miskin tersebut. Oleh karena itu Rasulullah Shallallahu 'Alahi Wa Sallam adalah manusia yang paling dermawan,dan lebih dermawan lagi adalah di bulan Ramadhan, ketika jibril sedang menemui beliau untuk saling memperdengarkan bacaan kitab suci Al-Qur'an.

5) Melatih Menahan Diri

Puasa akan melatih seorang muslim untuk belajar mengekang jiwa, menguasainya, serta mampu menahan diri, sehingga kemudian mengendalikan dan mengarahkannya kepada kebaikan dan kebahagiaan. Sebab, jiwa itu memang selalu saja mengajak kepada hal-hal yang buruk, kecuali yang dirahmati oleh Allah. Jika seseorang membiarkan jiwa lepas begitu saja, maka berarti mengantarkan dirinya kepada kebinasaan, sedangkan jika mampu mengendalikan dan menguasainya, maka seseorang akan mampu menggiring dirinya kepada tingkatan yang paling tinggi.

6) Menghilangkan Sifat Sombong

Hikmah puasa yang lainnya adalah menyadarkan diri dan menghilangkan sifat kesombongan, sehingga akan tunduk kepada kebenaran. Rasa kenyang, banyak minum serta banyak bersetubuh dengan istri, masing-masing akan menimbulkan kesenangan yang kelewat batas, kesombongan, keangkuhan dan kecongkakan terhadap manusia lain, juga terhadap kebenaran. Sebab, jika jiwa membutuhkan hal-hal semacam ini, maka seseorang akan menyibukkan diri untuk meraihnya. Jika ada kesempatan baginya untuk melakukan hal itu, maka seseorang akan memandang bahwa dirinya telah beruntung karena meraih apa yang diinginkannya sehingga merasa gembira dengan kegembiraan yang tercela serta sombong, sehingga hal inilah yang menyebabkan kehancurannya. Orang yang terjaga adalah orang yang dipelihara oleh Allah subhanahu wa ta'ala.

7) Menyempitnya Jalur Syaithon

Hikmah puasa yang lainnya adalah bahwa pembuluh darah akan menyempit manakala seseorang itu lapar dan dahaga, sehingga jalan setan dalam tubuh manusia pun menjadi sempit. Sebab setan itu berjalan di dalam tubuh anak Adam pada pembuluh darah, sebagaimana yang disebutkan dalam Shahihain dari Rasulullah shallallahu 'alaihi wa sallam. Dengan demikian bisikan-bisikan setan akan berhenti karena seseorang itu menjalankan puasa, demikian juga kerasnya syahwat dan amarah akan melentur pecah.

8) Manfaat Kesehatan

Hikmah puasa yang lainnya adalah adanya manfaat-kesehatan yang disebabkan mengurangi makan, mengistirahatkan alat pencernaan serta mengedapkan sebagian dari kelembaban-kelembaban dan ampas-ampas yang merugikan badan, dan sebagainya. Betapa besar hikmah yang telah digariskan oleh Allah, dan betapa bermanfaatnya syariat yang dibuat oleh Allah untuk makhluk-Nya.

9) Diampuninya Dosa yang Lalu

Di antara keutamaan puasa di bulan ramadhan adalah menjadi penyebab diampuninya 
dosa dan dihapuskanya kesalahan-kesalahan. Artinya, pelaksanaan puasa yang didasari oleh keimanan kepada Allah dan kerelaan atas kewajiban puasa yang dibebankan atas dirinya serta karena mengharap dan menghitung pahala yang akan diberikan oleh Allah, tidak benci terhadap kewajiban ini dan juga tidak ragu terhadap pahalanya. Jika hal-hal tersebut dilakukan, maka Allah akan memberikan ampunan kepadanya atas dosa yang telanjur ia lakukan.

10) Pahala yang Tidak Terbatas

Keutamaan puasa Ramadhan lainnya adalah bahwa pahalanya tidak terbatas dengan jumlah tertentu, akan tetapi orang yang berpuasa akan diberi pahala tanpa hitungan. Dalam hadits riwayat Muslim disebutkan yang artinya "Setiap amal perbuatan anak Adam menjadi miliknya yang dilipat gandakan kebaikannya (pahalanya) sepuluh hingga tujuh ratus kali lipat. Allah berfirman yang artinya "Kecuali puasa, karena sesungguhnya ia milik-Ku dan Aku akan membalasnya sendiri, Orang yang berpuasa itu meninggalkan nafsu dan makanannya demi Aku,"

b. Nilai Ibadah Shalat Malam

Qiyam Ramadhan meliputi shalat pada awal dan akhir malam bulan Ramadhan. Dengan demikian, shalat terawih termasuk bagian dari qiyam Ramadhan. Maka seyogyanya seorang muslim bersemangat untuk mengerjakan, memperhatikan serta berharap mendapatkan pahala dari Allah Subhanahu wa ta'ala atas ibadah shalat malam di bulan Ramadhan ini. Malam-malam itu jumlahnya terbatas, sehingga orang beriman yang berakal harus pandaipandai memanfaatkannya sebelum hilang kesempatannya. Shalat itu dinamakan tarawih karena orangorang biasanya mengerjakan shalat ini dengan panjang. Setiap kali mereka selesai mengerjakan empat rakaat, mereka pun istirahat sebentar. 34 Nilai ibadah shalat malam yang terdapat dalam kitab majālis syahru ramadhān untuk menyempurnakan ibadah fardhu, Allah memberikan pujian kepada pelakunya, diampuni dosa-dosa yang telah lalu dan wanita boleh shalat tarawih di masjid.

c. Nilai ibadah membaca al-Qur'an

Ramadhan disebut sebagai bulan al-Qur'an, karena pada bulan itu Allah menurunkan al Qur'an, sebagai petunjuk bagi umat manusia sekaligus sebagai penyembuh bagi orang yang beriman dari berbagai macam penyakit, baik rohani maupun jasmani dan memperjelas jalan kebajikan, Allah Ta'ala berfirman yang artinya "Beberapa hari yang ditentukan itu ialah) bulan Ramadhan, bulan yang di dalamnya diturunkan (permulaan) al-Qur'an sebagai petunjuk bagi manusia dan penjelasanpenjelasan mengenai petunjuk itu dan pembeda (antara yang haq dan bathil)."

Oleh karena itu, seorang muslim harus menjadikan al-Qur'an sebagai bacaan harian pada bulan Ramadhan, senantiasa merenungi kandungannya dan menjadikan al-Qur'an sebagai sumber kebenaran dan pedoman hidup. Nilai ibadah membaca al-Qur'an yang terkandung dalam kitab majālis syahru ramadhān, yaitu: menjadi sebaik-baik orang dan bersama Malaikat yang nulia. Dua pahala ini, salah satunya merupakan balasan dari membaca AlQur'an itu sendiri, sedangkan yang kedua adalah atas kesusahan dan keberatan yang dirasakan oleh pembacanya.

d. Nilai Ibadah Zakat Fitri

Zakat fitri ialah infak wajib atas setiap Muslim dengan kadar yang sudah jelas dan harus ditunaikan sebelum sholat Idul Fitri kemudian diberikan kepada pihak tertentu. Zakat fitri wajib bagi setiap Muslim baik budak, merdeka, laki-laki, wanita, anak kecil atau orang dewasa sejak terbenam matahari akhir bulan ramadhan dan lebih utama jika dibayarkan sebelum keluar shalat idul fitri dan boleh dibayarkan dua hari sebelum hari raya, hingga imam naik mimbar berdasarkan penegasan Ibnu Umar radhiallahu anhu yang artinya "Rasulullah mewajibkan zakat fitri (yaitu) satu sha' kurma, atau satu sha' gandum bagi budak, orang merdeka, laki-laki, wanita, anak kecil dan orang dewasa dari kalangan kaum muslimin, dan 
menyuruh agar ditunaikan sebelum orang-orang keluar untuk shalat (Idul Fithri)".

Nilai ibadah zakat fitri yang terkandung dalam kitab majālis syahru ramadhān yaitu berbuat baik dan menyantuni orang-orang fakir dan mencegah mereka dari meminta-minta pada hari raya, sehingga mereka pun bisa turut menyertai orang-orang kaya dalam kebahagian dan keceriaan dalam suasana hari raya, sehingga yang namanya hari raya adalah untuk semua. Hikmah lainnya adalah menyandang sifat akhlak luhur, murah hati, dan suka menghibur hati orang lain. Di samping itu juga akan menyucikan orang yang berpuasa dari kekurangan, kesiasiaan atau bahkan dosa yang mungkin dilakukannya selama menjalankan puasa. Juga untuk menunjukkan rasa syukur terhadap nikmat Allah dengan selesainya pelaksanaan puasa Ramadhan maupun berbagai amal shalih yang dilaksanakan didalamnya.

e. Nilai Ibadah I'tikaf

Nilai ibadah i'tikaf yang terkandung dalam kitab majālis syahru ramadhān adalah bersungguh-sungguh dalam mengerjakan amalan ibadah di sepuluh hari terakhir di bulan Ramadhan. Salah satu keistimewaan sepuluh hari terakhir bulan Ramadhan ini adalah bahwa Nabi shalallahu alaihi wa sallam senantiasa meningkatkan kesungguhan (mujahadah) di dalam beramal, dengan melakukan amalan yang lebih banyak lagi dari hari-hari selainnya. Dalam Shahihain disebutkan bahwa Aisyah berkata yang artinya "Ketika telah masuk sepuluh hari terakhir bulan Ramadhan, maka Rasulullah Shalallahu Alaihi wa Sallam mengencangkan sarung, menghidupkan malam dan membangunkan keluarganya."

Kesungguhan beliau ini meliputi segala bentuk kesungguhan di dalam melaksanakan berbagai jenis ibadah, baik yang berupa shalat, membaca Al-Qur'an, berzikir, sedekah dan sebagainya. Sebab, Nabi Shalallahu Alaihi wa Sallam ketika itu mengecangkan sarung, yang berarti meninggalkan istri-istri beliau untuk mengisi waktu sepenuhnya dengan ibadah shalat dan zikir. Termasuk keistimewaan sepuluh hari terakhir dari bulan Ramadhan ini adalah bahwa Nabi mengerjakan iktikaf di dalamnya. I'tikaf merupakan bagian dari ibadah sunah yang didasarkan pada Kitab Allah dan Sunnah Rasul-Nya. Allah subhanahu wa ta'ala berfirman dalam surat Al Baqarah yang artinya "(tetapi) Janganlah kamu campuri mereka itu, sedang kamu beri'tikaf dalam masjid."

Rasulullah shalallahu alaihi wa sallam dan para sahabat melaksanakan iktikaf, begitu juga kaum muslimin sesudah zaman mereka. Dalam Shahihain diriwayatkan hadits dari Aisyah radhiallahu anha bahwa ia berkata yang artinya "Rasulullah Shalallahu Alaihi wa Sallam melakukan iktikaf pada sepuluh hari terakhir bulan Ramadhan sampai beliau diwafatkan oleh Allah Subhanahu wa ta'ala. Sesudah itu, istri-istri beliau beri'tikaf pula sepeninggalan beliau."

\section{Simpulan}

Terdapat lima nilai-nilai pendidikan ibadah dalam kitab majālis syahru ramadhān, yaitu (a) nilai pendidikan ibadah puasa, meliputi mendekatkan diri kepada Allah, melahirkan ketaqwaan, hati selalu berdzikir, mengetahui kebesaran nikmat Allah, melatih menahan diri, diampuni dosadosa, pahala yang tidak terbatas, (b) nilai pendidikan ibadah shalat malam, meliputi diampuni dosa-dosa yang lalu, menyempurnakan ibadah fardhu, Allah memberikan pujian kepada pelakunya, (c) nilai pendidikan ibadah membaca Al-Qur'an, meliputi menjadi sebaik-baik orang, bersama malaikat yang mulia, (d) nilai pendidikan ibadah zakat fitri, menyantuni orang-orang fakir dan mencegah mereka meminta-minta di hari raya, turut membahagiakan mereka, menyucikan puasa dari kesia-siaan (e) nilai pendidikan ibadah i'tikaf, bersungguh-sungguh beramal disepuluh hari terakhir bulan Ramadhan. 


\section{Daftar Pustaka}

al Anwar, Z. (2018). Syarat Diterimanya Ibadah. At-Taqwa. http://at-taqwa.or.id/syarat-diterimanyasuatu-ibadah/

Asa, A. I. (2019). PENDIDIKAN KARAKTER MENURUT KI HADJAR DEWANTARA DAN DRIYARKARA. Jurnal Pendidikan Karakter, 9(2). https://doi.org/10.21831/jpk.v9i2.25361

Febriansyah, A. (2017). Tinjauan Atas Proses Penyusunan Laporan Keuangan Pada Young Enterpreneur Academy Indonesia Bandung. Jurnal Riset Akuntansi, 8(2). https://doi.org/10.34010/jra.v8i2.525

Lismijar, L. (2019). Pembinaan Sikap Ikhlas Menurut Pendidikan Islam. Intelektualita, 5(02), 12.

Ma'ruf, M. (2016). Pemikiran Pendidikan Abu a'La Al Maududi (Analisis Kritis Atas Pembaharuan Sistem Pendidikan Abu a'La Al Maududi. In At-Turats (Vol. 3, Issue 1). https://doi.org/10.24260/at-turats.v3i1.272

Mansir, F. (2018). Psikis : Jurnal Psikologi Islami Vol. 4 No. 1Juni 2018: 61-73. Psikis, 4(1), 61-73.

Miswanto, A. (2016). Tanawu' Al-Ibadah Di Muhammadiyah: Studi Terhadap Konsep Haji Tamattu' Dengan Satu Sa'i Hasil Ijtihad Kh. Zen Fanani Magelang. Cakrawala: Jurnal Studi Islam, 11(1), 5175. https://doi.org/10.31603/cakrawala.v11i1.100

Muttaqien, G. A. (2019). PANDANGAN SYED MUHAMMAD NAQUIB AL-ATTAS TENTANG ISLAMISASI ILMU. Jaqfi: Jurnal Aqidah Dan Filsafat Islam, 4(2), 93-130. https://doi.org/10.15575/jaqfi.v4i2.9458

Prasanti, D. (2018). Model - Model Penelitian Tindakan Kelas. Jurnal Ilmu Komunikasi, 6(1), 13-21.

Ramanda, R., Akbar, Z., \& Wirasti, R. A. M. K. (2019). STUDI KEPUSTAKAAN MENGENAI LANDASAN TEORI BODY IMAGE BAGI PERKEMBANGAN REMAJA. JURNAL EDUKASI: Jurnal Bimbingan Konseling, 5(2), 121. https://doi.org/10.22373/je.v5i2.5019

Saifudin Hakim, M. (2019). Dua Hikmah Penciptaan Manusia. Muslim.Or.Id. https://muslim.or.id/47867-dua-hikmah-penciptaan-manusia.html

Sari, D. A. (2019). Makna Agama dalam Kehidupan Modern. Cakrawala: Jurnal Studi Islam, 14(1), 1623. https://doi.org/10.31603/cakrawala.v14i1.2483

Subrata, S. A., \& Dewi, M. V. (2017). Puasa Ramadhan dalam Perspektif Kesehatan: Literatur Review. Khazanah: Jurnal Studi Islam Dan Humaniora, 15(2), 241. https://doi.org/10.18592/khazanah.v15i2.1139

Syamsudin. (2019). Pembinaan Agama Islam Dalam Upaya Mencegah. Fitrah, 10(1), 81-97.

Ulinnuha, R. (2016). Max Scheler Dan Relevansinya Pada Praxis Inter-Faith. Religi Studi Agama-Agama, 12(1), 59-73. 